\title{
THE FLEXIBILITY OF CURRICULUM FOR PERSONALISED LEARNING
}

\author{
Lina Kaminskiene \\ Vytautas Magnus University, Lithuania \\ Maria Jose DeUrraza \\ Vytautas Magnus University, Lithuania
}

\begin{abstract}
The paper discusses two main approaches to personalised learning through humanistic and functionalist approaches and tries to identify the shared areas. The paper argues that these areas are related to the development of a flexible curriculum and are focused on learner's needs and potentials, learner's ownership of the learning process, recognition of learner's pace and assessing personal progress. The paper is based on literature review, trying to systemise current theoretical and practical approaches to personalised learning.

Keywords: personalised learning, learner-centred pedagogy, curriculum.
\end{abstract}

\section{Introduction}

Personalised learning is typically defined as a strategy to respond to the diversity of learners and to actualize their opportunities in the most appropriate form to achieve their learning goals. The idea of personalised learning has become particularly actualised in the recent years. Although there is an increasing interest on personalised learning, the scientific literature is limited in providing models of its implementation and thus, this phenomenon still remains under-researched. Practices are rather scarce which could be explained by the fact that personalised learning as a concept is not very clearly defined. The difficulty of defining personalisation arises from its varied implementation in educational practice.

Most definitions of personalised learning are complex and reveal the main components of personalisation. Understanding and revealing diverse aspects of personalisation in education will help to identify it from the related teaching strategies, mainly individualisation. In personalised learning approach it is important to seek interaction, cooperation and involvement of each learner, however, it needs further research how much flexibility in curriculum should be ensured to address these needs.

The paper aims to investigate personalised learning practices, mainly focusing on general education level. For reaching this aim, the following objectives were defined: 
1) Discuss variations of the concept of personalised learning through humanistic and functionalist approaches.

2) Identify shared attributes of personalised learning which contribute to the development of flexible curriculum.

The paper is based on literature review, trying to systemise current theoretical and practical approaches to personalised learning. We referred to holistic and functionalist perspectives as proposed by Mincu (2012a; 2012b) to analyse different characteristics of personalised learning. This allowed us to define attributes of flexible curriculum which helps practical implementation of personalised learning models.

\section{Literature review}

Nowadays different concepts are used for the personalisation of education: personalised, individualised, tailored, self-regulated learning. Somehow, they are familiar and simultaneously, represent diverse conceptualizations. However, how we could know, which one reflects properly the aim of personalised learning? Which one reflects the concept from its essence? Watkins (2012) express this misunderstanding in the following quotation:

One more recent development creates a further hijack of personalised learning and is indicated in the view of this term which is emerging in the UK. Taking as an indicator of the 100,000 UK web pages, which use the term:

- $\quad 36 \%$ are associated with 'individual';

- $\quad 35 \%$ are associated with ICT/web/e-learning;

- $\quad 17 \%$ mention the classroom, mostly in passing. (Watkins, 2012, p. 7)

Still today we find these approaches to the concept and the confusion has not been solved. A research done by Monica E. Mincu (2012a) for the collection of articles called Personalisation of Education in contexts, Policy Critique and theories of personal improvement, gives scope to an almost recent situation in the study and the uses of this concept in different countries. Her work summits with her article doing a mapping of the different conceptualisations and practices of personalised learning. The use of the term in her research centres on the word personalisation, what is not a reduction, otherwise is a border concept that joins different combinations and describes the theories in their essence. It signifies that using the words education, learning, teaching, instruction together to 'personalised' concept, automatically refers to conceptualisations and strategies of implementation. In the article Mapping meanings of personalisation, Mincu (2012b) attempts to do an outline of the uses of the concept and the theoretical background managed by the authors. The analysis done gives, as a result, a conceptual diagram of categories for the use of the concept 'personalisation'. Among seven authors, she noticed several recurrent terms, which are 
dichotomised, combined or used as synonymous. This categorisation shows the diverse applications of the concept and the strategies that they intend. Mincu (2012a) reflects these matches:

- Personalisation versus individualisation;

- Individualisation and socialisation;

- $\quad$ Individualisation = personalisation;

- Individualised instruction and personalised learning.

In her study, Mincu (2012b) founds other keywords, which frame units of study. One of them is the conception of personalisation as a universal approach or as a pedagogical strategy targeted for particular pupils (Mincu, 2012b). This perception refers to the inclusion of pupils with disabilities in the mainstream of the school and defines the paradigm of teaching in/for diversity. Other keywords found in the different studies are the result of the logical or coherent implementation of the different conceptualisations and the fulfilling of the needs of education in the current times. To underline the study of the concept is important to use such kind of categories to define the lines of research and the frame for clear argumentations.

Analysing the concept of personalised learning, it is still needed a background of its history and the evolution of the concept. To situate the beginning of the term, it is necessary to classify two more categories demarcated by Mincu (2012b): humanist and functionalist. Making a broad distinction, the humanistic perspective talks about a person-centred perspective, and the functionalist, a learner-centred one. Both perceptions offer changes in education, both focus the attention on the learners, and both concentrate in the fulfilment of their needs. Nevertheless, the differences arise from the key values that structure the diverse applications.

The child-centred or learner-centred pedagogy is simultaneously focused on each individual and in the process of learning. It suggests the shift between teacher-centred education, to the full awareness of the learner. Chocarro, González-Torres and Sobrino (2007) make a comparative description of these two pedagogic perspectives. While the learner is the subject who learns in both propositions, the concept of learning differs. In the teacher-centred context, learning is the acquisition of knowledge, attitudes and strategies by the learner. In the learner-centred pedagogy, learning is the internal construction of knowledge by the learner. Another important differentiation is the definition of learning process goals, strategies and contexts. In the first perspective, it is the school curriculum, which indicates the outlines, while in the second approach it is radically the learner (Chocarro et al., 2007). The last feature is the main category which leads to a conceptualisation of personalised learning because the centre is in the learner's voice and his or her capacity of decision above the process of 
learning. Co-production, co-learning, learners' ownership of the learning process are concepts, which arise with the flourish of this approach. The knot that connects learner-centred and personalised learning bases on the importance given to the learner and his responsibility in the learning process. However, they are not synonyms because one precedes the other. Personalised learning appears because of the shift made by the learner-centred pedagogy.

Returning to the functionalist aspect, there should be remarked a difference within learner s voice and learner's choice. It could be the main distinction, and somehow, a fake shift from learner-centred to personalised learning. Emphasizing the learner's choice rather than voice, we find the broad scope of a modern conception of personalised learning as a product of marketisation of the school. The word choice refers to many aspects: learner as a consumer, school efficacy, user-centric education, modernisation, etc. (Hartley, 2008). These terms relate to a proposition, which concentrates on the learner's needs, however, in the aim to satisfy and create an atmosphere of learning just for me, just by me. In this perspective, there is no pedagogical theory and the goal is the development of schooling (Mincu, 2012b).

Another characteristic of functionalism is the pragmatic overview, which sees personalisation as an individualistic performance that tries to reach school targets, special needs groups. This way of personalisation appears to find heterogeneity teaching solutions and an inclusive view of education. Personalised assessment, flexible curriculum and the use of ICT means are the main elements of this perspective. This part of functionalism includes a pedagogical theory or strategy that includes different methods for personal assessment. In this case, we talk about functionalism from the use of the word as a perspective of functional; reminding what has a utilitarian purpose.

Humanist approach to personalised learning allows to connect the personal world of the learner and the way it shapes the process of learning. In the year 2017, UNESCO published a document entitled 'Personalised Learning' explaining the main features of this educational perspective:

'for an education to be meaningful, it needs to be personal: we cannot learn well if we do not see the relevance of what we are learning and how it applies to our personal situations'.

This outlook gives the idea to deep on a theory, which puts the centre in the person and its personal situation in the frame of learning processes. He or she, together with the teacher, with classmates, in a school environment, construct one's way of learning, being the owner of the process.

A humanist approach of personalisation of learning focuses on the idea of educating the whole person and the personal development. The learner has to develop cognitive abilities and concurrently, other dimensions of his personality. Therefore, the personal improvement leads him to better academic achievements. 
This point of view shaped by a philosophical tradition mainly stands on the ideas of personalism. Personalism is the philosophical theory, which keynote is the person. The human person surpasses all the other objects of knowledge and nature beings. This theory affirms that the human being is creative, and it implies that his actions make him a unique self (Mounier, 1989).

Singularity is a basis for the personalised learning strategy because it helps to identify the singular needs and the potentials of each learner. The idea of education one size fits for all, changed with the child-centred pedagogy, and the focus on the learner improved the level of consideration to each pupil. Personalisation expects to bring into focus each person among a group, and then he or she is not any more one among others (Camps-Bansell, 2018). This proposition mainly recognises the uniqueness of individual persons and the development of their life. It signifies that there are not exactly equal persons and, consequently, the treatment with each one should be particular. The total actuality, the whole world of a person, should not be identified by rules, by common standards; willingly it has to be studied individually, considering each person.

The faculty to make decisions is a key concept in personalism. In the field of education, it refers to the personal development of the learners. Considering treating learner as a person, the authors affirm that he constructs his personality with his decisions and acts. Not shaped by the outside, but it arises from himself, and education awakes it (Peters, 1977; Mounier, 1989). Therefore, the goals of education do not address just knowledge, but furthermore, the needs to develop other dimensions of the personality as the affections, the will, the behaviour, and socialisation. Learning is not just a collection of practical knowledge, which is going to be useful in the practical world. Learning is seen as the way of development of the learner as a person who needs the tools to work and those tools are not only knowledge but also an educated, fulfilled personality.

\section{Flexibility of curriculum: the shared points in different conceptualisations}

Even though there are dichotomies within the different insights of personalisation, there are some repeated features which affects the elements of curriculum making it flexible enough to address the following challenges:

- Consideration of learner's needs and potentials;

- Learner's ownership of the learning process;

- Recognition of learner's pace;

- Assessment of a personal progress.

The individual attention to the learner is an essential characteristic of childcentred learning. Working in the classroom is necessary to observe the different ways of working, recognizing the diverse methods of learning. The awareness of 
each pupil's needs helps them to feel understood, and to reach the academic achievements. The principal stands of recognition are observation and hearing the learner's voice: What catches his attention? Which environment does he need? What topics does he find interesting? These questions at one moment demarked the definition of child-centred education, though the difference is on using they (about the pupils) or he-she (about one pupil). The personalised learning pedagogy addresses these issues concerning one learner individually, instead of the whole group together as makes the child-centred approach.

Considering the voice of learners, curriculum development is a collaborative process between teachers and pupils. It is a dynamic creation attending the needs of students and their abilities for each subject.

The literature referred to personalised learning, frequently mentions the cocreation of knowledge as a core aspect of its pedagogy. The importance of cocreation bases on the fact that learners have the capability of decision making. As the learner can decide, he is responsible for his acts and can collaborate in the process of learning. Education is a process where two persons assume the task to learn and cooperate to achieve that goal (Carbajo-López, 2004). Collaboration requires engagement sense from the student and support from the teacher (Kaminskienè \& Khetsuriani, 2019).

The feature of decision making, as is mentioned, implies responsibility, and it is what configures ownership and autonomy. Both mentioned characteristics presuppose the capacity to modify the circumstances around the learner as, his curriculum (Camps-Bansell, 2018).

The groups of schooling do not guarantee homogeneity. Indeed, it is a characteristic not found in the classrooms. Each pupil has one's learning strategies, modes of work and pace for solving different tasks. Regarding differences within the same age, related to skills, personal development, cognitive achievements, it is impossible to look forward to uniformity. Moreover, it is not desirable to think that teachers tend to standardise and allow stereotypes in education under the concept of one size fits for all (Bernardo et al., 2011). Therefore, the application of pedagogical methods respecting the different paces and learning strategies is the core of personalisation of education. Educational institutions should promote adaptability for each pupil in terms of dynamism and interactive learning (Bernardo et al., 2011) and to stimulate and reinforce personal improvement, it is necessary flexibility for the particular circumstances of each learner.

One of the key features of personalized learning is the flexibility of various teaching / learning strategies that allow the implementation of a personalised learning plan. It also encourages learners to take responsibility for and sustain their learning. The scientific literature suggests that being able to design and implement a personal plan has a positive effect on learner motivation (Nethoc, 
2017). Learners are motivated to succeed in their learning - they face their own choices and decisions. The school and the teacher do not determine the content and pace of learning, so the learner is expected to be responsible for managing learning - the more the learner demonstrates their motivation and the selfregulation it exerts, the more they are given learning autonomy (Campbell et al., 2007).

In personalised learning assessment is organised when the teacher and the learner formulate clear criteria detailing the outcomes and demonstrating the quality of the assignment (Zmuda, Curtis, \& Ullman, 2015). The learner should understand these criteria so that he / she can clearly organise the learning. However, developing a variety of assessment criteria descriptions based on subject-specific outcomes and interdisciplinary key competences to assess each student's personal learning experience poses a real challenge for the teacher. Such descriptors are necessary to ensure that the assessment is informative and reveals personal learning in the area of subject-specific outcomes and, if included, of interdisciplinary key competences. It is important that all learners have a continuous record of the learning process in a form of their choice, such as activity diaries, feedback from peers and similar. The assessment evidences allow learners to see progress in implementing the development plan. Progress is one of the most important elements of assessment (Zmuda, Curtis, \& Ullman, 2015). The practice of personalised learning gives priority to formative assessment that is multifaceted and opens up the whole process of personal learning (Zmuda, Curtis, \& Ullman, 2015). However, it is also advisable to apply summative assessmentat the end (Karmeshu, Raman, \& Nedungadi, 2012) in order to benchmark learning outcomes defined in the curriculum.

\section{Conclusions}

Different researchers link personalised learning with individualised learning, while others, on the contrary, try to mark a borderline between them. Two approaches, the humanistic and the functionalist, both focus on the learners and both concentrate on fulfilling their needs. However, they also have distinct differences. In humanistic perspective personalised learning it is the learner who together with the teacher, with classmates construct personal way of learning. Personalisation of learning focuses on the idea of educating the whole person and the personal development. The learner has to develop cognitive abilities and concurrently, other dimensions of his personality. In functionalist approach, personalised learning is associated with co-production, co-learning, learners' ownership of the learning process. Personalised assessment, flexible curriculum and the use of ICT means are the main elements of this perspective. 
Notwithstanding different approaches, they also share common characteristics, which were defined as follow: consideration of learner's needs and potentials; learner's ownership of the learning process; recognition of learner's pace; assessment of personal progress. These attributes change practices in implementation of the curriculum and thus, contribute to its flexibility, which allows fulfilling diverse learning needs.

\section{References}

Bernardo, J., Javaloyes, J.J., Calderero, J.F., Muñoz, M.M., \& Castellanos, A. (2011). Educación personalizada: principios, técnicas y recursos. Madrid: Síntesis.

Campbell, R.J., Robinson, W., Neelands, J., Hewston, R., \& Mazzoli, L. (2010). Personalised learning: ambiguities in theory and practice. British Journal of Educational Studies, 55, 135-154.

Camps-Bansell, J. (2018). Educación personalizada y diferenciada. Madrid: Digital Reasons.

López, F.C. (2004). La comunicación entre el profesor-tutor y los alumnos. Reflexiones sobre la tutoría en los centros estatales españoles. ESE: Estudios Sobre Educación, 7, 129-142.

Chocarro, E., González-Torres, M., \& Sobrino, Á. (2007). Nuevas orientaciones en la formación del profesorado para una enseñanza centrada en la promoción del aprendizaje autorregulado de los alumnos. Estudios sobre Educación, 12. DOI:10.17770/ sie2019vol2.3708

Hartley, D. (2008). Education, markets and the pedagogy of personalisation. British Journal of Educational Studies, 56(4), 365-381.

International Bureau of Education. Training Tools for Curriculum Development (2017). Training Tools for Curriculum Development: Personalized Learning. Retrieved from https://unesdoc.unesco.org/ark:/48223/pf0000250057/PDF/250057eng.pdf.multi.page=1 andzoom=auto,-16,842.

Kaminskienè, L., \& Khetsuriani, N. (2019). Co-creation of learning as an engaging practice. Society, Integration, Education: proceedings of the international scientific conference, 2, 191-199. Rēzekne: Rēzeknes Tehnolog̣iju akadēmija.

Karmeshu, Raman, R. \& Nedungadi, P. (2012). Modelling diffusion of a personalized learning framework. Education Tech Research Dew, 60, 585-600.

Mincu, M.E. (2012a). Mapping meanings of personalisation. In Personalisation of Education in Contexts. Brill Sense. DOI:10.2753/EUE1056-4934410103

Mincu, M.E. (2012b). Editorial Introduction. In Personalisation of Education in Contexts: Policy critique and theories of personal improvement. Rotterdam: Sense Publishers. DOI:10.2753/EUE1056-4934410103

Mounier, E. (1989). Personalism. University of Notre Dame Press.

Netcoh, S. (2017). Balancing freedom and limitations: A case study of choise provision in a personalized learning class. Teaching and Teacher Education, 66, 383-392. Retrieved from https://www-sciencedirect-com.ezproxy.vdu.lt:2443/science/article/pii/ S0742051X16302748

Peters, R.S. (1977). Education and the Education of Teachers. Routledge and Kegan Paul.

Watkins, C. (2012). Personalisation and the Classroom Context. In Personalisation of Education in Contexts (pp.1-18). Rotterdam: Sense Publishers.

Zmuda, A., Curtis, G., \& Ullman, D. (2015). Learning personalized. The Evolution of the Contemporary Classroom. San Francisco: Jossey-Bass. 